\title{
An Experimental Research of Small Hydropower Plant Investments Selection in Turkey by Carrot $^{2}$, DEXi, DEXiTree
}

\author{
Burak Omer Saracoglu \\ Orhantepe Mahallesi, Tekel Caddesi, Geziyolu Sokak, Dragos, Kartal, Istanbul, Turkey
}

Email address:

burakomersaracoglu@hotmail.com

To cite this article:

Burak Omer Saracoglu. An Experimental Research of Small Hydropower Plant Investments Selection in Turkey by Carrot ${ }^{2}$, DEXi, DEXiTree. Journal of Investment and Management. Vol. 4, No. 1, 2015, pp. 47-60. doi: 10.11648/j.jim.20150401.17

\begin{abstract}
Nowadays, human daily lives depend very much to electricity. Hence, electricity generation plays a key role not only in countries' economies, but also in people's welfare and comfort in any region. This situation isn't also different for Turkey. Turkish electricity generation policy gives the opportunity for foreign and domestic private investments plans and schemes. Private investors have many private power plant investment options to invest in Turkey. One of the main groups is hydropower plants. Small hydropower plant investments are grouped under the hydropower plant investments. Their characteristics are very different from other types of hydropower plants. This experimental research study investigates the possibility of using a qualitative Multi Attribute Decision Making (MADM) model based on DEXi (Decision EXpert for Education) and DEXiTree software. Attributes in the current experimental research model are analyzed by help of a text mining tool Carrot $^{2}$. In the experimental case study, the most appropriate small hydropower plant investments amongst five alternative ones at the predevelopment investment stages (an assumption) in Turkey are evaluated, and prioritized by help of seventeen basic factors (catchment area, project runoff, net head, discharge, firm energy, secondary energy, investment cost, river basin, conveyance structure, community attitude, transportation, topography, geology, security conditions, terrorism conditions, protected areas, substation conditions) based on the experimental DEXi decision model. There are some interesting findings such as Option 5 gets the highest priority in the overall experimental decision model. Similarly, Option 5 has the very good preference in the objective attributes evaluation. Option 3 comes afterwards with the good preference. But, both Option 4 and Option 5 get the good preference in the subjective attributes evaluation. The DEXi model file (*.dxi) is also presented to readers for giving opportunity to readers for preparing their models based on this experimental research model. This experimental research study is seen as another very small research step to deeply understand the nature of the small hydropower plants investments decisions in the way of developing an autonomous computer based intelligent decision support system for the real world cases.
\end{abstract}

Keywords: Carrot $^{2}$, DEXi, DEXiTree, Investment, Multi Attribute Decision Making, Private, Small Hydropower, Turkey

\section{Introduction}

Today, electricity is a must for our world. It is consumed at homes, on streets, at factories, and almost anywhere. Researchers work to understand deeply the relations between the electricity demand and the causes and the reasons of this electricity demand. Some researchers indicate that one of the main important factors of the electricity demand is the population growth $[1,2,3]$. The historical data of the annual population in Turkey is given by "Tab. 1".

The annual population growth in this study is calculated by the equations "(1)" and "(2)". The annual population growth in Turkey is presented in "Fig. 1".
Table 1. Annual total population in Turkey (data:[4], generated by the Microsoft Office 2007 Word http://www.microsoft.com/en-us/).

\begin{tabular}{ll}
\hline Year & Population (total) \\
\hline 2003 & 65.938 .265 \\
2004 & 66.845 .635 \\
2005 & 67.743 .052 \\
2006 & 68.626 .337 \\
2007 & 69.496 .513 \\
2008 & 70.363 .511 \\
2009 & 71.241 .080 \\
2010 & 72.137 .546 \\
2011 & 73.058 .638 \\
2012 & 73.997 .128 \\
\hline
\end{tabular}




$$
\begin{aligned}
& \text { POY } i+1-\text { POY } i=\text { POD } \\
& \text { POD } / \text { POY } i=\text { POG }
\end{aligned}
$$

PO is the annual population, $\mathrm{Y}$ is the year and $\mathrm{i}$ stands for 2003, 2004, 2005, 2006 until 2012. D is the difference. G stands for the growth. For example; the annual population difference in Turkey between 2003 and 2004 (907.370) is calculated as the annual population in Turkey in 2004 (66.845.635) subtracted from the annual population in Turkey in 2003 (65.938.265). The annual population growth in Turkey between 2003 and $2004(1,38 \%)$ is calculated as the division of the annual population difference in Turkey between 2003 and 2004 (907.370) by the annual population in Turkey in 2003 (65.938.265).

The total annual population growth in the current study is calculated by the equation "(3)" and the arithmetic mean of the annual population growth in this study is calculated by the equation “(4)".

$$
\begin{aligned}
& \sum \text { POG } \mathrm{j}=\text { TPOG } \\
& \text { TPOG } / \sum \mathrm{j}=\text { AMAPOG }
\end{aligned}
$$

$\mathrm{TPO}_{\mathrm{G}}$ is the total annual population growth in Turkey. $\mathrm{j}$ stands for the instances of years, and $\mathrm{AMAPO}_{\mathrm{G}}$ is the arithmetic mean of the annual population growth. The $\mathrm{TPO}_{\mathrm{G}}$ between 2003 and 2012 in Turkey is found $11,60 \%, \sum \mathrm{j}$ is counted as 9 and finally $\mathrm{AMAPO}_{\mathrm{G}}$ in this period is calculated as $1,29 \%$.

As a result, it is believed that the electricity consumption in Turkey will increase in the mid to long term under these conditions (if conditions will be the same or similar). Hence, this subject takes the attention and the interest of this study.

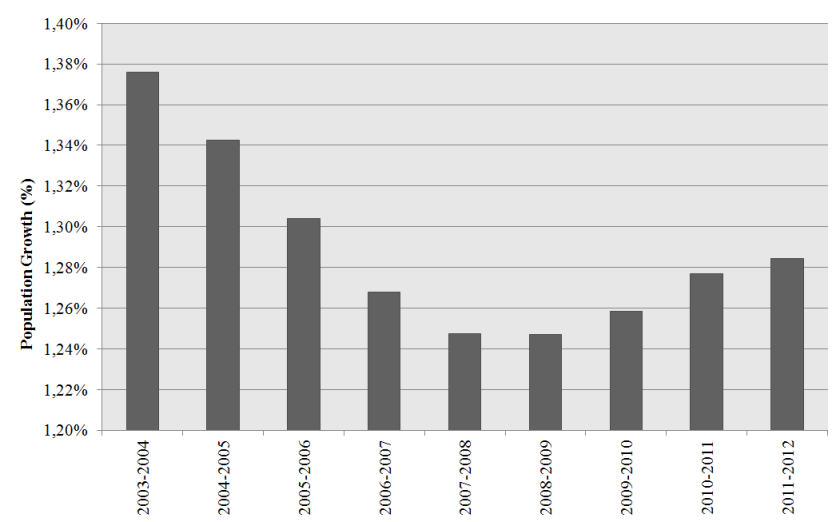

Figure 1. Total population growth in Turkey (generated by the Apache OpenOffice 4.1.1 Calc http://www.openoffice.org/ \& the Paint.NET http://www.getpaint.net/index.html).

When the private electricity generation market in Turkey is investigated in detail, it is observed that there are several types of power plants investments alternatives. For instance, coal power plants, natural gas power plants, hydropower plants and wind power plants.

Foreign and domestic private investors may invest in several different ways, whichever the power plant type they want to, according to the Electricity Market Legislations in
Turkey (visit [5]). Hydropower plant investments are one of the attractive ones due to their relatively low levelized cost of electricity (LCOE) (visit [6]).

The LCOE is simply calculated as in the equation "(5)" to "(12)" (visit [7]).

$$
\begin{aligned}
& (\mathrm{OCC} \times \mathrm{CRF}+\mathrm{FOMC})=\mathrm{EP} 1 \mathrm{~N} \\
& \mathrm{i} \times(1+\mathrm{i})^{\wedge} \mathrm{n}=\mathrm{CRFN} \\
& {\left[(1+\mathrm{i})^{\wedge} \mathrm{n}\right]-1=\mathrm{CRFD}} \\
& \mathrm{CRFN} / \mathrm{CRFD}=\mathrm{CRF} \\
& (8760 \times \mathrm{CF})=\mathrm{EP} 1 \mathrm{D} \\
& \mathrm{EP} 1 \mathrm{~N} / \mathrm{EP} 1 \mathrm{D}=\mathrm{EP} 1 \\
& (\mathrm{FC} \times \mathrm{HR})=\mathrm{EP} 2 \\
& (\mathrm{EP} 1+\mathrm{EP} 2+\mathrm{VOMC})=\mathrm{LCOE}
\end{aligned}
$$

OCC represents the overnight capital cost $(\$ / \mathrm{kW}$ : United States Dollar per kilowatt), CRF represents the capital recovery factor, FOMC is for the fixed O\&M cost $(\$ / \mathrm{kW}-\mathrm{yr}$ : United States Dollar per kilowatt per year), and EP1N represents the numerator in the equation "(5)" and "(10)". CRF is calculated by the equation "(6)", "(7)", and "(8)" (visit [8]). i represents the interest rate, $\mathrm{n}$ represents the number of annuities received in the equations "(6)" and "(7)". CRFN stands for the numerator of the capital recovery factor in the equation "(6)" and "(8)". CRFD stands for the denominator of the capital recovery factor in the equation "(7)" and "(8)". 8760 is the number of hours in a year, CF is for the capacity factor (between 0 and 1) and EP1D is for the denominator in the equation "(9)" and "(10)". EP1 stands for the equation part 1 (the first part of the equation) in the equation "(10)" and "(12)". FC stands for the fuel cost (\$/MMBtu: dollars per million british thermal units) and HR stands for the heat rate $(\mathrm{Btu} / \mathrm{kWh}$ : british thermal units per kilowatt-hour) in the equation "(11)". These two terms are only for the non-renewable power plants. Renewable power plants such as hydro, solar and wind don't consume any fuel. EP2 is for the equation part 2 (the second part of the equation) in the equation "(11)" and "(12)". VOMC stands for the variable O\&M cost ( $\$ / \mathrm{kWh})$ in the equation "(12)". Thus, LCOE is a good cost evaluation criteria for the power plant types. It can be calculated by some practical tools such as the Simple Levelized Cost of Energy Calculator (visit [9]).

According to the practical industry experience and information, it can be underlined very well that private investors should always look for some private hydropower investment alternatives for their real world mid to long term investment portfolio. Thus, this study pays attention in this subject.

Hydropower plants are usually classified based on their installed power or capacity (kW: kilowatt) as large, medium, small, mini, micro and pico [10,11]. In this study, small hydro power plants are accepted as the hydropower plants, which have the installed capacity between 1 megawatt and 
10 megawatts (1 MW $<\mathrm{P} \leq 10 \mathrm{MW})$.

Small hydropower plant investments segment is an appropriate choice for small to midsize private investors in the world, because they need relatively small initial capital and they have relatively small LCOE values.

In Turkey, they have some additional advantages such as a great number of private small hydropower plant projects have been granted their licenses from EMRA and then some of them are already connected to the national electric grid after their preconstruction and construction periods and also these small hydropower plants are decentralized considering their locations (visit [12], [13]).

Foreign and domestic private investors can own them as one or buy their shares and become shareholders of them (see acquisition, joint venture, merger, portfolio, and share terms on [14] to understand the ways to become real world investors).

Hence, small hydropower plant investments should be studied in a detailed manner. This study is one of the studies that investigates the small hydropower plant investments.

There are many small hydropower plant investment problems to be researched such as the investment policy research area, the small hydropower design field, the small hydropower investment analysis research area, the investment forecasting and modeling field, and the real world investment selection research topics.

This study focuses clearly in the private small hydropower plants investments selection research field (only private and only small hydropower).

There are also many approaches and methodologies under this field. This paper only investigates the Multi Attribute Decision Making (MADM), or the Multi criteria Decision Making (MCDM).

There are a lot of methods under the MADM, or the MCDM. A few of them are the Analytic Hierarchy Process (AHP) [15], the Analytic Network Process (ANP) [16], The DEX (Decision EXpert) or the DEXi (Decision EXpert for Education) [17], the Elimination and Choice Translating Reality (Elimination Et Choix Tradusiant la Realite) (ELECTRE) [18], and the Preference Ranking Organization METHod for Enrichment Evaluations (PROMETHEE) [19]. In this paper, the private small hydropower plant investment selection problem in Turkey by the DEX (Decision EXpert) or the DEXi (Decision EXpert for Education) is studied and presented in a detailed, but simplified manner.

An experimental research DEXi decision model is built and an experimental research case study with seventeen criteria and five alternative or options (private small hydropower plant investments) is conducted in this study.

This paper has four sections. The literature review is the next section. The experimental research model and its case study are explained in the third section. Finally, the conclusions and future research are discussed and presented in last section.

\section{Literature Review}

The previous research studies in this specific field (private small hydropower plant investments selection by a multi attribute decision making method DEXi) are tried to be reviewed by help of some scientific online database and journal websites (fifteen scientific websites). These websites are presented in "Tab. 2".

Table 2. Scientific websites reviewed in this study (review until 17/07/2015) (generated by the Microsoft Office 2007 Word).

\begin{tabular}{ll}
\hline Title & Website Address \\
\hline ACM Digital Library & http://dl.acm.org/ \\
ASCE Online Research Library & http://ascelibrary.org/ \\
American Society of Mechanical & http://asmedigitalcollection.asme.org \\
Engineers & http://journals.cambridge.org \\
Cambridge Journals Online & http://doaj.org \\
Directory of Open Access Journals & www.emeraldinsight.com \\
Emerald Insight & http://scholar.google.com.tr \\
Google Scholar & www.hindawi.com \\
Hindawi Publishing Corporation & www.inderscience.com \\
Inderscience Publishers & www.sciencedirect.com \\
Science Direct & www.sciencepublishinggroup.com \\
Science Publishing Group & www.springer.com/gp \\
Springer & www.tandfonline.com \\
Taylor \& Francis Online/Journals & http://onlinelibrary.wiley.com \\
Wiley-Blackwell/Wiley Online & www.worldscientific.com \\
Library & World Scientific Publishing
\end{tabular}

The search queries on these scientific websites are defined based on author's experiences during author's previous research studies. These search queries are given by "Tab. 3". There are ten queries, which hopefully cover the whole publications in this field (general point of method and its applications). These search queries are directly typed on the search query boxes and full truncation option is preferred on the search preferences, so that all of the journal papers, the conference papers, the books, and all other means and types of documents are searched in the current study. The review is then followed by the title, the abstract and the key words investigations. If any clues are found for any relation with the current subject, then full documents are tried to be found for detail review purposes.

Table 3. Search queries in this study (review until 17/07/2015) (generated by the Microsoft Office 2007 Word).

\begin{tabular}{ll}
\hline No $(\#)$ & Search Queries \\
\hline$\# 1$ & "small hydropower" AND "DEXi" \\
$\# 2$ & "small hydropower" AND "Decision EXpert" \\
$\# 3$ & "power" AND "DEXi" \\
$\# 4$ & "power" AND "Decision EXpert" \\
$\# 5$ & "project" AND "DEXi" \\
$\# 6$ & "project" AND "Decision EXpert" \\
$\# 7$ & "investment" AND "DEXi" \\
$\# 8$ & "investment" AND "Decision EXpert" \\
$\# 9$ & "electric" AND " DEXi" \\
$\# 10$ & "electric" AND "Decision EXpert" \\
\hline
\end{tabular}


There are 16, 13, 33, 26, 13, 13, 3, 9 search results (hit rate of 2.402.988 documents) respectively for queries \#3, \#4, \#5, $\# 6, \# 7, \# 8, \# 9, \# 10$ on the ACM Digital Library. There are only few studies (3 documents) in the agricultural and information and communication technology (ICT) research fields according to the title abstract and keywords review.

There are 1, 2, 1 search results respectively for queries \#4, \#6, \#8 on the ASCE Online Research Library. None of these publications are related with the method and its applications.

There isn't any search results found for any of the queries on the American Society of Mechanical Engineers.

There are $62,62,62,62,62,2,6,1$ search results respectively for queries $\# 3, \# 4, \# 5, \# 6, \# 7, \# 8, \# 9, \# 10$ on the Cambridge Journals Online. None of these publications are related with the method and its applications.

There is only 1 search result (hit rate of 1.887 .399 documents) for query \#5 on the Directory of Open Access Journals. This study is in the agricultural research field.

There are 10, 2, 8, 5, 3 search results respectively for queries $\# 4, \# 5, \# 6, \# 8, \# 10$ on the Emerald Insight. None of these publications are related with the method and its applications.

There are 1, 1.650 (visit [20]), 527, 1.160, 562, 222, 230, 984,147 search results respectively for queries \#1, \#3, \#4, \#5, $\# 6$, \#7, \#8, \#9, \#10 on the Google Scholar. There are some studies (45 documents) in the agriculture (business as usual agriculture and energy crops for biogas), decision support, education, environment, finance, health, human resources/career development, media, and military research fields according to the title abstract keywords review and full text document review.

There isn't any search results found for any of the queries on the Hindawi Publishing Corporation.

There isn't any search results found for any of the queries on the Inderscience Publishers.

There are 137, 118, 114, 134, 14, 73, 57, 19 search results (hit rate of 13.397.561 documents) respectively for queries \#3, \#4, \#5, \#6, \#7, \#8, \#9, \#10 on the Science Direct. There are only few studies (11 documents) in the agricultural, education, health and ICT research fields according to the title, abstract and keywords review.

There isn't any search results found for any of the queries on the Science Publishing Group.

There are 45, 206, 81, 385, 15, 135, 14, 115 search results respectively for queries $\# 3, \# 4, \# 5, \# 6, \# 7, \# 8, \# 9, \# 10$ on the Springer. There are only few studies (10 documents) in the agricultural, health and ICT research fields according to the title, abstract and keywords review.

There are 2, 9, 21, 2, 11, 3, 2 search results respectively for queries $\# 4, \# 5, \# 6, \# 7, \# 8, \# 9$, \#10 on the Taylor \& Francis Online/Journals. There are only few studies ( 6 documents) in the agricultural, health, transportation and ICT research fields according to the title, abstract and keywords review.

There are $62,76,66,73,12,43,22,11$ search results respectively for queries $\# 3, \# 4, \# 5, \# 6, \# 7, \# 8, \# 9, \# 10$ on the Wiley-Blackwell/Wiley Online Library. There are only few studies (2 documents) in the agriculture, human resources, and research fields according to the title, abstract and keywords review.

There are 7, 2, 2, 6, 2, 1, 1 search results respectively for queries \#3, \#4, \#5, \#6, \#7, \#9, \#10 on the World Scientific Publishing. None of these publications are related with the method and its applications.

This literature review shows that this study is most probably the first study in its research field (in general point of view with the tags of power plant, investment, DEXi).

The DEXi is first presented in 2000s [17]. It is developed based on the DEX and the DECMAK [21]. The DECMAK, proposed in 1980's, is developed in the United Kingdom by Efstathiou and Rajkovic and in Slovenia by Rajkovic and Bohanec [21, 22]. The DEX (Decision EXpert) is developed to be an expert system shell in 1987 and the DEXi is first introduced to research community in 2000's by Jereb, Bohanec, and Rajkovic [23, 24]. The DEX is a DOS tool and deals with the probabilistic and fuzzy distribution of values [17]. The DEXi is the most powerful one amongst these three tools. The detailed information about these methods can be gathered from Dr. Marko Bohanec's website (Jožef Stefan Institute, Department of Knowledge Technologies, Ljubljana, Slovenia: http://kt.ijs.si/MarkoBohanec/)

\section{Experimental Research Model, Case, Results, and Discussion}

The experimental research model and the experimental case study in this study is based on author's previous studies by different methods such as the one with the ELECTRE III, the ELECTRE IV, Shannon's Entropy objective criteria weighting and Saaty's subjective criteria weighting (ELECTRE: Elimination and Choice Translating Reality: Elimination Et Choix Tradusiant la Realite) (see [25]) and the one with the AHP (Analytic Hierarchy Process) (see [26]). In that base models, there are 17 criteria as presented in given by "Tab. 4". These factors (attributes) aren't revised and changed in this study. These attributes are organized by the approach of clustering to developed the current DEXi structure according to the DEXi's main structural guidelines and recommendations. One of the recommendations is as below:

A well organized DEXi model has two to four descendants for each of its aggregate nodes.

According to this recommendation, these 17 attributes are accepted as the basic attributes of the current experimental research model. The basic attributes and possible aggregation nodes are at first investigated by help of Carrot $^{2}$.

"Carrot ${ }^{2}$ is an open source software project that includes several text clustering algorithms. Among these are bisecting K-means, Suffix Tree Clustering and Lingo algorithm" [41, 42, 43]. Each basic attribute is searched on the Carrot $^{2}$ desktop and the related documents with this attribute and their words or phrases are found on the visualization tools as shown in "Fig. 2", "Fig. 3", and "Fig. 4". Generally speaking, this activity should be performed for improving the perception of experts and decision makers on the attributes. 


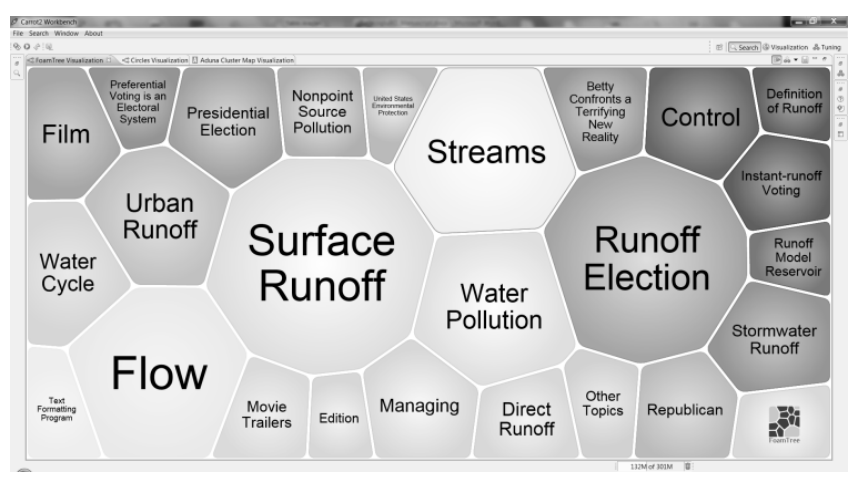

Figure 2. Carrot2-workbench "runoff" FoamTree visualization (generated by the Carrot2 http://carrot2.org \& the Paint.NET).

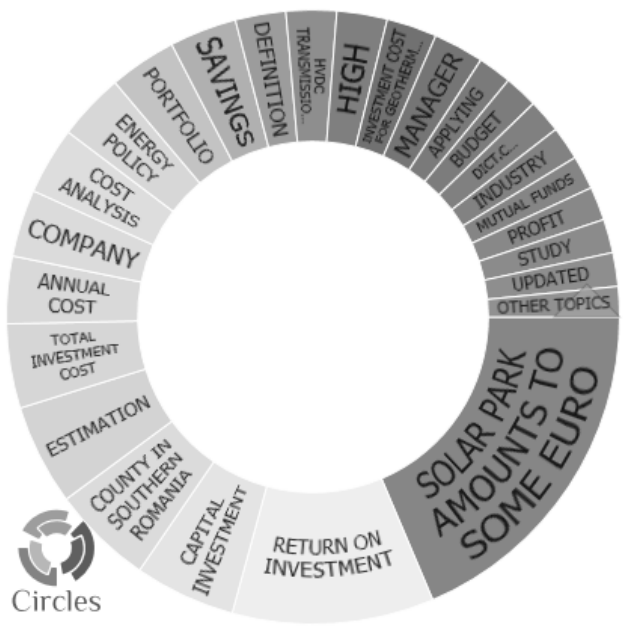

Figure 3. Carrot2-workbench "investment cost" Circles visualization (generated by the Carrot $2 \&$ the Paint.NET).

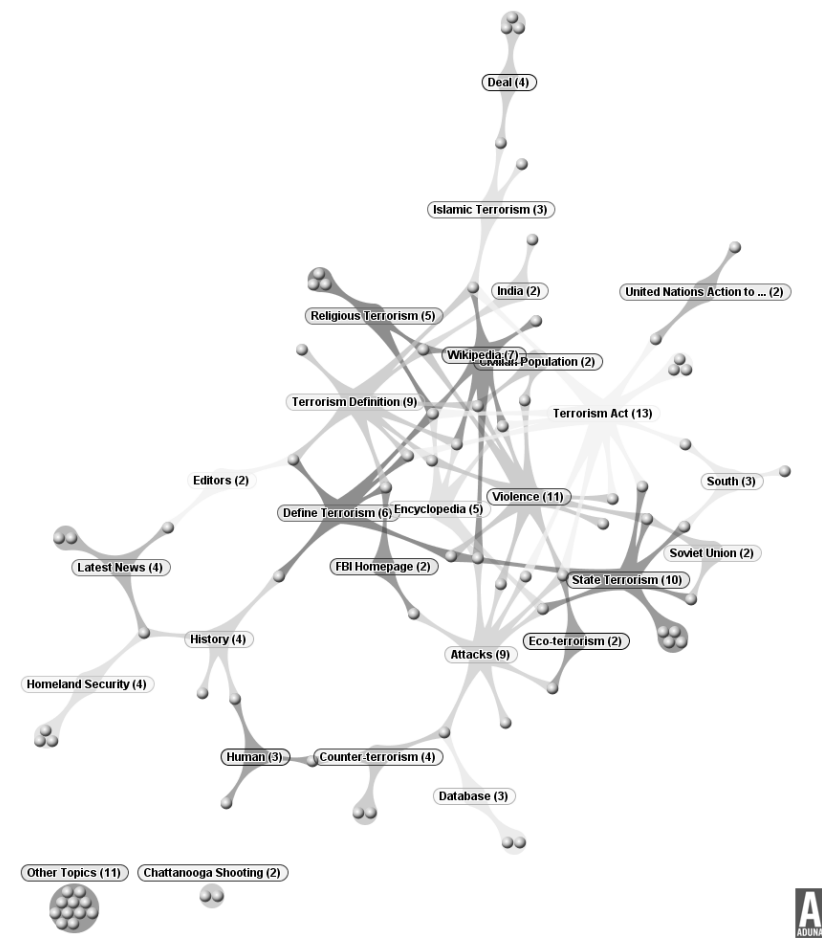

Figure 4. Carrot2-workbench "terrorism" Aduna Cluster Map visualization (generated by the Carrot $2 \&$ the Paint.NET).
The first clustering approach for these attributes depends on their objectivity and subjectivity. Catchment area $\left(\mathrm{km}^{2}\right)$, project runoff $\left(\mathrm{hm}^{3}\right)$, net head $(\mathrm{m})$, discharge (rate of flow) $\left(\mathrm{m}^{3} / \mathrm{s}\right)$, firm energy $(\mathrm{GWh})$, secondary energy $(\mathrm{GWh})$, and investment cost (million USD) attributes are objective attributes. Other attributes are subjective attributes. Hence, the current experimental research DEXi structure should consider this discrimination.

The second clustering approach depends social features and none social features. Community attitude, security conditions and terrorism conditions attributes are grouped under social features. Other ones are none social features.

The third clustering approach is about the essential items of the private small hydropower plants and complementary features of the private small hydropower plants. River basin, catchment area $\left(\mathrm{km}^{2}\right)$, project runoff $\left(\mathrm{hm}^{3}\right)$, net head $(\mathrm{m})$ and discharge (rate of flow) $\left(\mathrm{m}^{3} / \mathrm{s}\right)$ attributes are at first investigated in the small hydropower plant development studies. Conveyance structures are designed and often revised several times during the design process. Investment cost (million USD) is calculated based on the designs and the costs (daily to annual changes during the whole process). These two attributes can be grouped under complementary features.

The fourth clustering approach is related with the electricity generation features. Firm energy (GWh) and secondary energy $(\mathrm{GWh})$ are the electricity generation features of the small hydropower plants. Others don't present the electricity generation.

The fifth clustering approach is related with the site or location essential items. Topography, geology, protected areas (conservation areas), substation conditions can be grouped under essential features of the private small hydropower plant sites.

As a consequence, the experimental research DEXi decision model starts with the "Private Small Hydropower Plant Preference" and it is modeled as in this paragraph.

It has two main aggregate nodes "Objective Attributes Evaluation" and "Subjective Attributes Evaluation" (according to two to four descendants).

The "Objective Attributes Evaluation" main aggregate node is divided into three sub aggregate node "Electricity Generation Features of Private Small Hydropower Plant Investment", that includes "Firm Energy (GWh)", and "Secondary Energy (GWh)" attributes, "River Basin Objective Features", that has "Catchment Area $\left(\mathrm{km}^{2}\right)$ ", and "Project Runoff $\left(\mathrm{hm}^{3}\right)$ " attributes, and finally "Private Small Hydropower Plant Main Objective Features", that includes "Net Head (m)", "Discharge (rate of flow) $\left(\mathrm{m}^{3} / \mathrm{s}\right)$ ", and "Investment Cost (million USD)" attributes.

The second main aggregate node "Subjective Attributes Evaluation" are divided into four sub aggregate node "Social Features of Private Small Hydropower Plant Site", that has three attributes as "Community Attitude", "Security Conditions", and "Terrorism Conditions", "Technical Evaluation Features of Private Small Hydropower Plant Site", that has three attributes "River Basin", "Topography", and "Geology", "Technical Evaluation Features of Private Small Hydropower Plant", which has two attributes "Conveyance 
Structure", and "Substation Conditions", and finally "General Evaluation Features of Private Small Hydropower Plant Site", that has two attributes as "Transportation" and "Protected Areas (conservation areas)".
The current experimental DEXi decision model is drawn by the DEXiTree Software

(http://kt.ijs.si/MarkoBohanec/dexitree.html) and shown in "Fig. 5".

Table 4. Attributes of the current experimental model (also details in [25, 26]) (generated by the Microsoft Office 2007 Word).

\begin{tabular}{|c|c|}
\hline Attributes & Terminological Description \\
\hline Catchment Area $(\mathrm{km} 2)$ & $\begin{array}{l}\text { "area drained by a river and all its tributaries" [27]. The practical usage in small hydropower } \\
\text { applications is considered for the attribute. }\end{array}$ \\
\hline Project Runoff (hm3) & $\begin{array}{l}\text { "Surface runoff is precipitation runoff over the landscape.", "Only about a third of the precipitation that } \\
\text { falls over land runs off into streams and rivers and is returned to the oceans. The other two-thirds is } \\
\text { evaporated, transpired, or soaks (infiltrates) into groundwater. Surface runoff can also be diverted by } \\
\text { humans for their own uses." [28]. The practical usage in small hydropower applications is considered } \\
\text { for the attribute. }\end{array}$ \\
\hline Net Head (m) & "gross head minus all hydraulic losses except those chargeable to the turbine." [29] \\
\hline Discharge (rate of flow) (m3/s) & $\begin{array}{l}\text { "Discharge is the volume of water moving down a stream or river per unit of time, commonly } \\
\text { expressed in cubic feet per second or gallons per day. In general, river discharge is computed by } \\
\text { multiplying the area of water in a channel cross section by the average velocity of the water in that } \\
\text { cross section" [30]. The practical usage in small hydropower applications is considered for the } \\
\text { attribute. }\end{array}$ \\
\hline Firm Energy (GWh) & "power delivered during a certain period of time with at least $90-95 \%$ certainty" [31] \\
\hline Secondary Energy (GWh) & difference between total energy generation (GWh) and firm energy generation (GWh) \\
\hline Investment Cost (million USD) & initial capital cost \\
\hline River Basin & characteristics of the river basin (see [22]) \\
\hline $\begin{array}{l}\text { Conveyance } \\
\text { Structure }\end{array}$ & weir, canal, tunnel, conduits, culverts, syphons, settling tanks, etc. (see [31, 32]) \\
\hline $\begin{array}{l}\text { Community } \\
\text { Attitude }\end{array}$ & "attitudes held by groups of people that live in communities" [33] \\
\hline Topography & $\begin{array}{l}\text { "the configuration of a surface and the relations among its man-made and natural features", "precise } \\
\text { detailed study of the surface features of a region" [35] }\end{array}$ \\
\hline Geology & $\begin{array}{l}\text { "In general, geology is the scientific study of the earth- the material of which it is made, the processes } \\
\text { that act on these materials, the products formed, and the history of the planet and its life forms since } \\
\text { origin. Geology now includes the study of other planets as well" [36] }\end{array}$ \\
\hline $\begin{array}{l}\text { Security } \\
\text { Conditions }\end{array}$ & $\begin{array}{l}\text { "The state of being free from danger or threat", "The safety of a state or organization against criminal } \\
\text { activity such as terrorism, theft, or espionage", "Procedures followed or measures taken to ensure the } \\
\text { security of a state or organization", "The state of feeling safe, stable, and free from fear or anxiety" [37] }\end{array}$ \\
\hline $\begin{array}{l}\text { Terrorism } \\
\text { Conditions }\end{array}$ & $\begin{array}{l}\text { "Terrorism has been described variously as both a tactic and strategy; a crime and a holy duty; a } \\
\text { justified reaction to oppression and an inexcusable abomination. Obviously, a lot depends on whose } \\
\text { point of view is being represented. Terrorism has often been an effective tactic for the weaker side in a } \\
\text { conflict. As an asymmetric form of conflict, it confers coercive power with many of the advantages of } \\
\text { military force at a fraction of the cost. Due to the secretive nature and small size of terrorist } \\
\text { organizations, they often offer opponents no clear organization to defend against or to deter.", "...there } \\
\text { are three key elements - violence, fear, and intimidation-and each element produces terror in its } \\
\text { victims.", " Terrorism is a criminal act that influences an audience beyond the immediate victim.", } \\
\text { "Those billion people watching were to be introduced to fear - which is terrorism's ultimate goal." [38] }\end{array}$ \\
\hline Protected Areas (conservation areas) & $\begin{array}{l}\text { "A protected area is a clearly defined geographical space, recognised, dedicated and managed, through } \\
\text { legal or other effective means, to achieve the long term conservation of nature with associated } \\
\text { ecosystem services and cultural values" [39] }\end{array}$ \\
\hline $\begin{array}{l}\text { Substation } \\
\text { Conditions }\end{array}$ & $\begin{array}{l}\text { "Substations are essential parts of the electrical distribution system. The link between high-voltage } \\
\text { transmission lines and low-voltage power systems is the substation." [40]. The practical usage in small } \\
\text { hydropower applications is considered for the attribute. }\end{array}$ \\
\hline
\end{tabular}




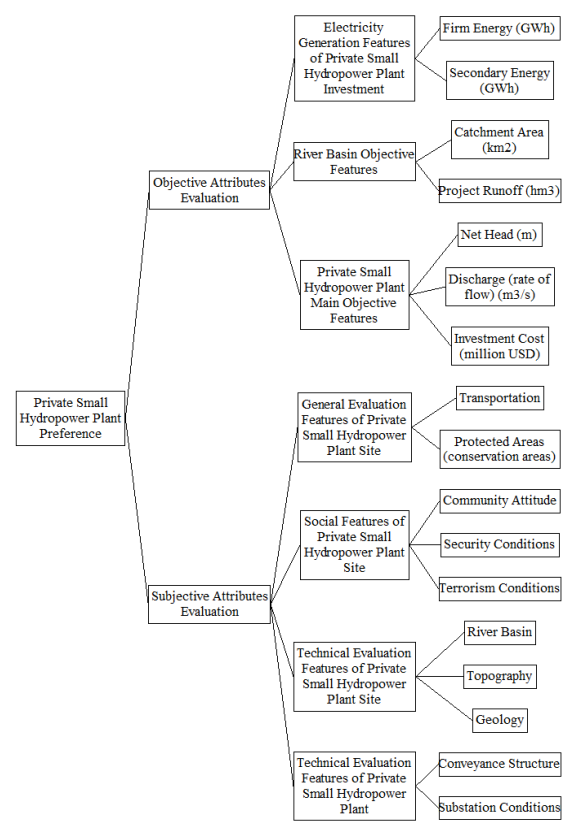

Figure 5. Experimental DEXi research decision model on DEXiTree (generated by the DEXi http://kt.ijs.si/MarkoBohanec/dexi.html \& the DEXiTree http://kt.ijs.si/MarkoBohanec/dexitree.html \& the Paint.NET).
The scales of attributes are very important in DEXi decision models like the other MADM models. The human's cognitive capability and limitations (human multitasking and working memory) are taken into account during modeling of the current scales. The increasing scales are preferred considering the human cognition limitations.

In addition, the current model by itself (structure of basic and aggregate attributes) and its scales are designed according to human cognitive capacity for processing information (short term memory capacity). The magical number $7,7 \pm 2$ rule is followed and obeyed in this study (see [44, 45, 46, 47].

The scale size of the basic attributes is limited with the least number of distinguishable values. The scale size of the sub aggregate nodes and aggregate nodes are increased gradually. The target attribute or objective or main aggregate node "Private Small Hydropower Plant Preference" is scaled as the lowest priority, the low priority, the normal priority, the high priority, and the highest priority. It is believed that these hedges and set of words for discrimination of the scales can represent the preferences very well for experts, decision makers and readers. The structure and the scales of attributes are presented by "Tab. 5".

Table 5. Attributes, main aggregate nodes, sub aggregate nodes and their scales (generated by the Microsoft Office 2007 Word).

\begin{tabular}{|c|c|}
\hline Aggregate Nodes/Attributes & Scale \\
\hline Private Small Hydropower Plant Preference & $\begin{array}{l}\text { +lowest priority(-); low priority; normal priority; high priority; } \\
\text { highest priority }(+)\end{array}$ \\
\hline Objective Attributes Evaluation & +very poor(-); poor; good; very good(+) \\
\hline Q Electricity Generation Features of Private Small Hydropower Plant Investment & $+\operatorname{low}(-) ;$ medium; high $(+)$ \\
\hline Firm Energy $(\mathrm{GWh})$ & $+\operatorname{low}(-) ; \operatorname{high}(+)$ \\
\hline Secondary Energy (GWh) & $+\operatorname{low}(-) ; \operatorname{high}(+)$ \\
\hline Q River Basin Objective Features & $+\operatorname{low}(-)$;medium; high $(+)$ \\
\hline Project Runoff $\left(\mathrm{hm}^{3}\right)$ & $+\operatorname{low}(-) ; \operatorname{high}(+)$ \\
\hline 口 Private Small Hydropower Plant Main Objective Features & $+\operatorname{low}(-) ;$ medium; high $(+)$ \\
\hline Net Head (m) & $+\operatorname{low}(-) ; \operatorname{high}(+)$ \\
\hline Discharge (rate of flow) $\left(\mathrm{m}^{3} / \mathrm{s}\right)$ & $+\operatorname{low}(-) ; \operatorname{high}(+)$ \\
\hline Investment Cost (million USD) & $+\operatorname{high}(-) ; \operatorname{low}(+)$ \\
\hline Subjective Attributes Evaluation & +very poor(-); poor; good; very good(+) \\
\hline 口 General Evaluation Features of Private Small Hydropower Plant Site & +unsuitable(-);probably suitable; suitable $(+)$ \\
\hline Protected Areas (conservation areas) & + many $(-) ;$ few $(+)$ \\
\hline 口 Social Features of Private Small Hydropower Plant Site & +unsuitable(-);probably suitable; suitable(+) \\
\hline Community & +neoative $(-) \cdot$ nositive $(+)$ \\
\hline Attitude & + negative $(-) ;$ positive $(+)$ \\
\hline Security Conditions & + poor(-); $\operatorname{good}(+)$ \\
\hline Terrorism Conditions & + poor(-); $\operatorname{good}(+)$ \\
\hline Q Technical Features of Private Small Hydropower Plant Site & +unsuitable(-);probably suitable; suitable(+) \\
\hline River Basin & + poor $(-) ; \operatorname{good}(+)$ \\
\hline Topography & + poor $(-) ; \operatorname{good}(+)$ \\
\hline Geology & + poor(-); $\operatorname{good}(+)$ \\
\hline o Technical Evaluation Features of Private Small Hydropower Plant & + poor(-); fair; good $(+)$ \\
\hline Conveyance Structure & + poor(-); $\operatorname{good}(+)$ \\
\hline Substation Conditions & +unsuitable $(-)$; suitable $(+)$ \\
\hline
\end{tabular}

After all of the scale of attributes are defined in this model, the utility functions are determined for the current DEXi decision model. The utility functions in DEXi is explained as "components of multi-attribute models that define the 
aggregation aspect of option evaluation. For each aggregate attribute $\mathrm{Y}$, whose descendants in the tree of attributes are $\mathrm{X}_{1}$, $\mathrm{X}_{2}, \ldots, \mathrm{X}_{\mathrm{n}}$, the corresponding utility function $\mathrm{f}$ defines the mapping: $f: X_{1} \times X_{2} \times \ldots \times X_{n} \rightarrow Y$ " and "a utility function maps all the combinations of the lower-level attribute values into the values of Y" [48]. The utility functions of this experimental model is presented in "Tab. 6".

By finalizing defining the aggregate nodes and attributes, deciding the scales of these aggregate nodes and attributes, and defining the utility functions, the current experimental DEXi decision model for private small hydropower plants investment selection can be used for the evaluation of the options in an experimental case.

There are five private small hydropower plant investment options in this experimental case study (Option 1 to Option 5). These private small hydropower plant investments are assumed that they are in their pre-development investment stages and free for sale by any means such as acquisitions, joint ventures, and mergers. Their data and information are gathered from several sources and presented by "Fig. 6" to "Fig. 12" (only objective attributes).

These objective attributes are directly evaluated based on these values, so that there isn't any additional efforts to be spent for the evaluation. The experts, decision makers and expert decision makers also don't need to evaluate these attributes.

The subjective attributes need to be evaluated in this experimental model. The evaluations are made one by one and presented by "Tab. 7" to "Tab. 16".

These evaluations are entered into the related cells on the DEXi Version 4.00 to get the results.

Table 6. Utility functions of the current experimental DEXi decision model (generated by the Microsoft Office 2007 Word)

\begin{tabular}{lll}
\hline Aggregate Nodes & Utility functions \\
\hline & 1 & $111+$ \\
2 & $121+$ \\
3 & $132+$ \\
4 & $142+$ \\
5 & $212+$ \\
6 & $222+$ \\
& 7 & $233+$ \\
Private Small Hydropower Plant & 8 & $243+$ \\
Preference & 9 & $313+$ \\
& 10 & $323+$ \\
& 11 & $334+$ \\
& 12 & $345+$ \\
& 13 & $413+$ \\
& 14 & $424+$ \\
& 15 & $435+$ \\
& 16 & $445+$ \\
& 1 & $1111+$ \\
& 2 & $1121+$ \\
Objective Attributes Evaluation & 3 & $1131+$ \\
& 4 & $1211+$ \\
& 5 & $1221+$ \\
6 & $1231+$ \\
& 7 & $1311+$ \\
& 8 & $1321+$ \\
& 9 & $1331+$ \\
\hline
\end{tabular}

\begin{tabular}{|c|c|}
\hline Aggregate Nodes & Utility functions \\
\hline & $10 \quad 2112+$ \\
\hline & $11 \quad 2122+$ \\
\hline & $12 \quad 2132+$ \\
\hline & $2212-$ \\
\hline & $2223+$ \\
\hline & $2233+$ \\
\hline & $2312+$ \\
\hline & $2323+$ \\
\hline & $2333+$ \\
\hline & $3112+$ \\
\hline & $3122+$ \\
\hline & $213133+$ \\
\hline & $22 \quad 3213+$ \\
\hline & $23 \quad 3223+$ \\
\hline & $24 \quad 3233+$ \\
\hline & $3313+$ \\
\hline & $3324+$ \\
\hline & $3334+$ \\
\hline & $111+$ \\
\hline Electricity Generation Features of & $122+$ \\
\hline Private Small Hydropower Plant & $3213+$ \\
\hline & $4 \quad 223-$ \\
\hline & $111+$ \\
\hline River Rasin Ohictive Features & $122+$ \\
\hline River Basin Objective Features & $212+$ \\
\hline & $223+$ \\
\hline & $1111+$ \\
\hline & $1122+$ \\
\hline & $1212+$ \\
\hline Private Small Hydropower Plant & $1223+$ \\
\hline Main Objective Features & $2112+$ \\
\hline & $2122+$ \\
\hline & $2212+$ \\
\hline & $2223+$ \\
\hline & $11111+$ \\
\hline & $11121+$ \\
\hline & $11131+$ \\
\hline & $11211+$ \\
\hline & $11221+$ \\
\hline & $11231+$ \\
\hline & $11312+$ \\
\hline & $11322+$ \\
\hline & $11332+$ \\
\hline & $10 \quad 12111+$ \\
\hline & $11 \quad 12121+$ \\
\hline & $12132+$ \\
\hline & $12211+$ \\
\hline & $14 \quad 12222+$ \\
\hline & $12232+$ \\
\hline Subjective Attributes Evaluation & $12312+$ \\
\hline & $17 \quad 12322+$ \\
\hline & $12332+$ \\
\hline & $13112+$ \\
\hline & $13122+$ \\
\hline & $13132+$ \\
\hline & $13212+$ \\
\hline & $13222+$ \\
\hline & $13232+$ \\
\hline & $13312+$ \\
\hline & $13322+$ \\
\hline & $13332+$ \\
\hline & $21112+$ \\
\hline & $29 \quad 21122+$ \\
\hline & $30 \quad 21132+$ \\
\hline
\end{tabular}




\begin{tabular}{|c|c|c|}
\hline \multirow{2}{*}{ Aggregate Nodes } & \multicolumn{2}{|c|}{ Utility functions } \\
\hline & 31 & $21212+$ \\
\hline & 32 & $21222+$ \\
\hline & 33 & $21232+$ \\
\hline & 34 & $21312+$ \\
\hline & 35 & $21322+$ \\
\hline & 36 & $21332+$ \\
\hline & 37 & $22112+$ \\
\hline & 38 & $22122+$ \\
\hline & 39 & $22132+$ \\
\hline & 40 & $22212+$ \\
\hline & 41 & $22223+$ \\
\hline & 42 & $22233+$ \\
\hline & 43 & $22312+$ \\
\hline & 44 & $22323+$ \\
\hline & 45 & $22333+$ \\
\hline & 46 & $23112+$ \\
\hline & 47 & $23123+$ \\
\hline & 48 & $23133+$ \\
\hline & 49 & $23212+$ \\
\hline & 50 & $23223+$ \\
\hline & 51 & $23233+$ \\
\hline & 52 & $23312+$ \\
\hline & 53 & $23323+$ \\
\hline & 54 & $23334+$ \\
\hline & 55 & $31112+$ \\
\hline & 56 & $31122+$ \\
\hline & 57 & $31132+$ \\
\hline & 58 & $31212+$ \\
\hline & 59 & $31222+$ \\
\hline & 60 & $31232+$ \\
\hline & 61 & $31312+$ \\
\hline & 62 & $31322+$ \\
\hline & 63 & $31332+$ \\
\hline & 64 & $32112+$ \\
\hline & 65 & $32122+$ \\
\hline & 66 & $32132+$ \\
\hline & 67 & $32212+$ \\
\hline & 68 & $32223+$ \\
\hline & 69 & $32233+$ \\
\hline & 70 & $32312+$ \\
\hline & 71 & $32323+$ \\
\hline & 72 & $32333+$ \\
\hline & 73 & $33112+$ \\
\hline & 74 & $33123+$ \\
\hline & 75 & $33133+$ \\
\hline & 76 & $33212+$ \\
\hline & 77 & $33223+$ \\
\hline & 78 & $33234+$ \\
\hline & 79 & $33313+$ \\
\hline & 80 & $33324+$ \\
\hline & 81 & $33334+$ \\
\hline General Evaluation Features of & 1 & $111+$ \\
\hline Private Small Hydropower Plant & 2 & $122+$ \\
\hline $\begin{array}{l}\text { Site } \\
\text { Sall }\end{array}$ & 3 & $212+$ \\
\hline & 4 & $223+$ \\
\hline & 1 & $1111+$ \\
\hline & 2 & $1122+$ \\
\hline & 3 & $1211+$ \\
\hline Social Features of Private Small & 4 & $1222+$ \\
\hline Hydropower Plant Site & 5 & $2111+$ \\
\hline & 6 & $2122+$ \\
\hline & 7 & $2211+$ \\
\hline & 8 & $2223+$ \\
\hline Technical Features of Private & 1 & $1111+$ \\
\hline Small Hydropower Plant Site & 2 & $1121+$ \\
\hline
\end{tabular}

\begin{tabular}{lll}
\hline Aggregate Nodes & Utility functions \\
\hline & 3 & $1211+$ \\
4 & $1222+$ \\
5 & $2111+$ \\
& 6 & $2122+$ \\
& 7 & $2212+$ \\
& 8 & $2223+$ \\
Technical Evaluation Features of & 1 & $111+$ \\
Private Small Hydropower Plant & 2 & $122+$ \\
& 3 & $211+$ \\
& 4 & $223+$ \\
\hline
\end{tabular}

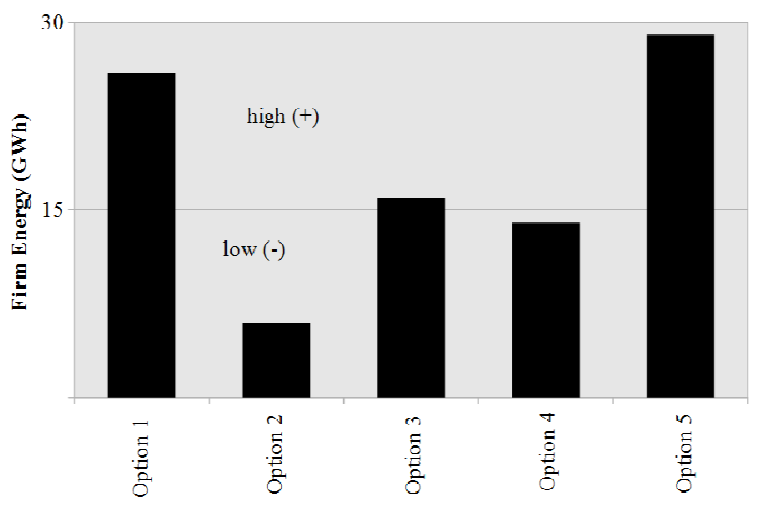

Figure 6. Firm energy (GWh) evaluation of options (generated by the Apache OpenOffice 4.1.1 Calc \& the Paint.NET).

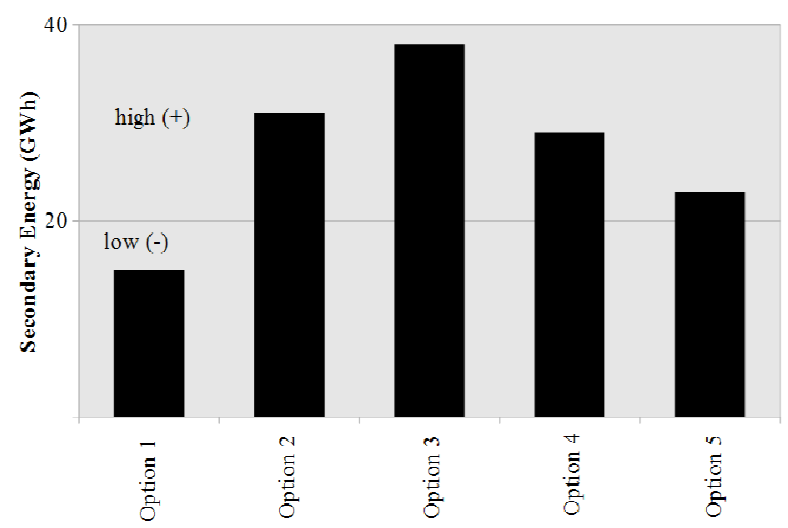

Figure 7. Secondary energy (GWh) evaluation of options (generated by the Apache OpenOffice 4.1.1 Calc \& the Paint.NET).

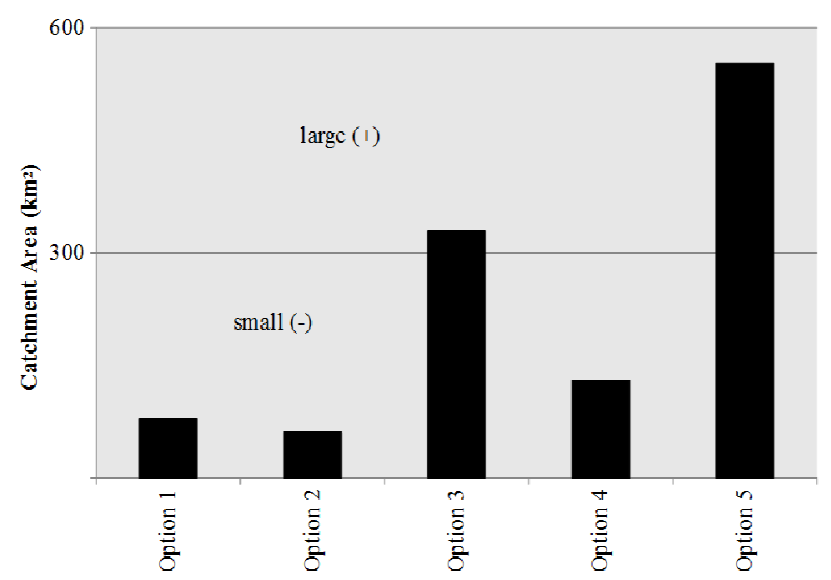

Figure 8. Catchment area $\left(\mathrm{km}^{2}\right)$ evaluation of options (generated by the Apache OpenOffice 4.1.1 Calc \& the Paint.NET). 


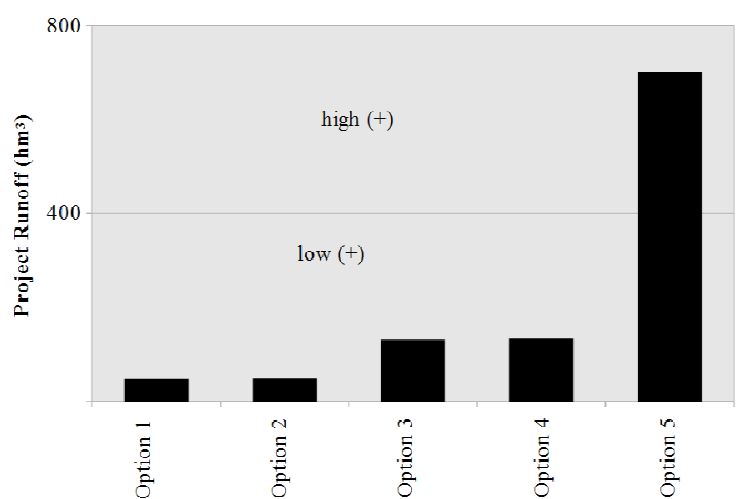

Figure 9. Project runoff $\left(\mathrm{hm}^{3}\right)$ evaluation of options (generated by the Apache OpenOffice 4.1.1 Calc \& the Paint.NET).

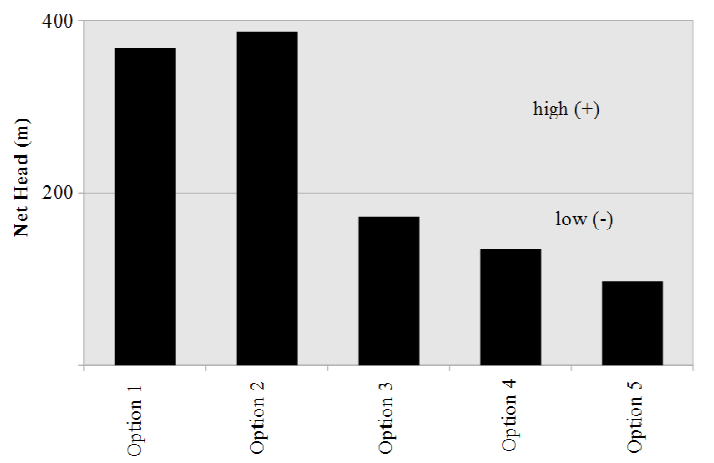

Figure 10. Net head (m) evaluation of options (generated by the Apache OpenOffice 4.1.1 Calc \& the Paint.NET).

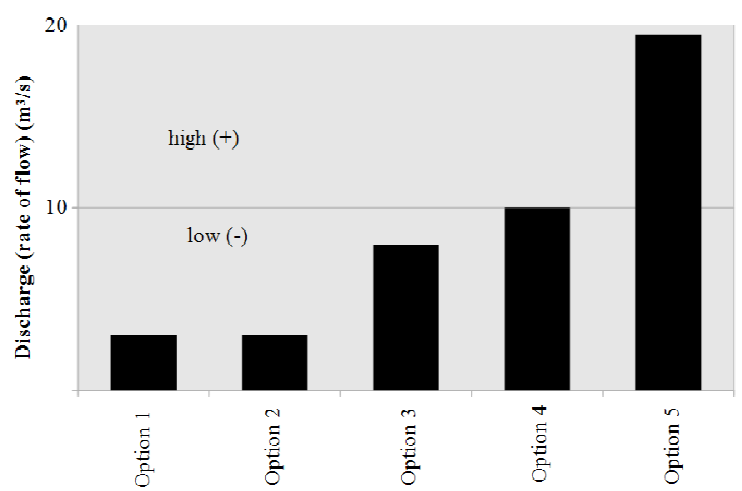

Figure 11. Discharge (rate of flow) $\left(\mathrm{m}^{3} / \mathrm{s}\right)$ evaluation of options (generated by the Apache OpenOffice 4.1.1 Calc \& the Paint.NET).

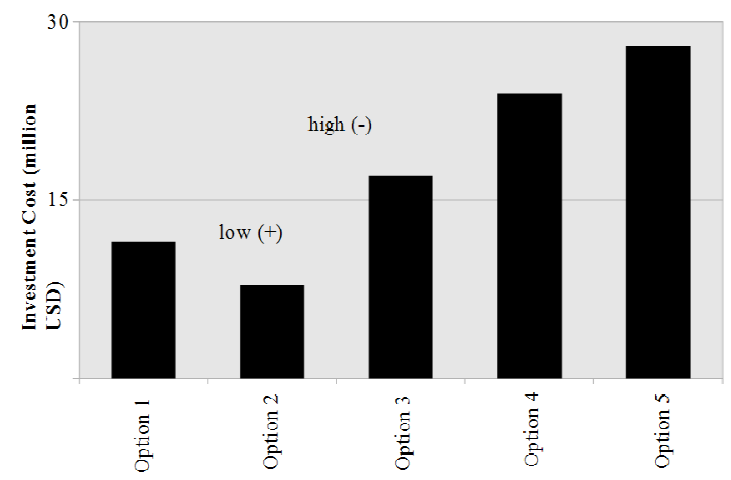

Figure 12. Investment cost (million USD) evaluation of options (generated by the Apache OpenOffice 4.1.1 Calc \& the Paint.NET).
Table 7. Subjective attributes evaluation of transportation (generated by the Microsoft Office 2007 Word).

\begin{tabular}{ll}
\hline Options & Evaluation \\
\hline Option 1 & $\operatorname{good}(+)$ \\
Option 2 & poor(-) \\
Option 3 & poor(-) \\
Option 4 & $\operatorname{good}(+)$ \\
Option 5 & $\operatorname{good}(+)$ \\
\hline
\end{tabular}

Table 8. Subjective attributes evaluation of protected areas (conservation areas) (generated by the Microsoft Office 2007 Word).

\begin{tabular}{ll}
\hline Options & Evaluation \\
\hline Option 1 & many(-) \\
Option 2 & many(-) \\
Option 3 & few $(+)$ \\
Option 4 & few $(+)$ \\
Option 5 & few $(+)$ \\
\hline
\end{tabular}

Table 9. Subjective attributes evaluation of community attitude (generated by the Microsoft Office 2007 Word).

\begin{tabular}{ll}
\hline Options & Evaluation \\
\hline Option 1 & positive( + ) \\
Option 2 & negative(-) \\
Option 3 & positive(+) \\
Option 4 & negative(-) \\
Option 5 & negative(-) \\
\hline
\end{tabular}

Table 10. Subjective attributes evaluation of security conditions (generated by the Microsoft Office 2007 Word).

\begin{tabular}{ll}
\hline Options & Evaluation \\
\hline Option 1 & $\operatorname{good}(+)$ \\
Option 2 & $\operatorname{good}(+)$ \\
Option 3 & poor(-) \\
Option 4 & $\operatorname{good}(+)$ \\
Option 5 & poor(-) \\
\hline
\end{tabular}

Table 11. Subjective attributes evaluation of terrorism conditions (generated by the Microsoft Office 2007 Word).

\begin{tabular}{ll}
\hline Options & Evaluation \\
\hline Option 1 & $\operatorname{good}(+)$ \\
Option 2 & $\operatorname{poor}(-)$ \\
Option 3 & $\operatorname{poor}(-)$ \\
Option 4 & $\operatorname{good}(+)$ \\
Option 5 & $\operatorname{good}(+)$ \\
\hline
\end{tabular}

Table 12. Subjective attributes evaluation of river basin (generated by the Microsoft Office 2007 Word).

\begin{tabular}{ll}
\hline Options & Evaluation \\
\hline Option 1 & $\operatorname{poor}(-)$ \\
Option 2 & $\operatorname{good}(+)$ \\
Option 3 & $\operatorname{poor}(-)$ \\
Option 4 & $\operatorname{good}(+)$ \\
Option 5 & $\operatorname{good}(+)$ \\
\hline
\end{tabular}


Table 13. Subjective attributes evaluation of topography (generated by the Microsoft Office 2007 Word).

\begin{tabular}{ll}
\hline Options & Evaluation \\
\hline Option 1 & $\operatorname{good}(+)$ \\
Option 2 & $\operatorname{poor}(-)$ \\
Option 3 & $\operatorname{poor}(-)$ \\
Option 4 & $\operatorname{good}(+)$ \\
Option 5 & $\operatorname{good}(+)$ \\
\hline
\end{tabular}

Table 14. Subjective attributes evaluation of geology (generated by the Microsoft Office 2007 Word).

\begin{tabular}{ll}
\hline Options & Evaluation \\
\hline Option 1 & $\operatorname{good}(+)$ \\
Option 2 & poor(-) \\
Option 3 & $\operatorname{poor}(-)$ \\
Option 4 & $\operatorname{good}(+)$ \\
Option 5 & $\operatorname{good}(+)$ \\
\hline
\end{tabular}

Table 15. Subjective attributes evaluation of conveyance structure (generated by the Microsoft Office 2007 Word).

\begin{tabular}{ll}
\hline Options & Evaluation \\
\hline Option 1 & $\operatorname{good}(+)$ \\
Option 2 & $\operatorname{good}(+)$ \\
Option 3 & poor(-) \\
Option 4 & poor(-) \\
Option 5 & poor(-) \\
\hline
\end{tabular}

Table 16. Subjective attributes evaluation of substation conditions (generated by the Microsoft Office 2007 Word).

\begin{tabular}{ll}
\hline Options & Evaluation \\
\hline Option 1 & unsuitable(-) \\
Option 2 & suitable(+) \\
Option 3 & suitable(+) \\
Option 4 & suitable $(+)$ \\
Option 5 & suitable $(+)$ \\
\hline
\end{tabular}

When only objective attributes evaluations are investigated as shown in "Fig. 14", Option 5 has the very good evaluation or preference. Option 3 comes after Option 5 with the good evaluation. Option 1, Option 2 and Option 4 have same evaluations as the poor preference. This approach shows that when only one objective attribute is evaluated the optimal solutions can't be reached in these kinds of problems, because one alternative may be good for one of the attribute or one group of attributes, but it may be bad for other ones or other groups. Hence, multi attribute decision making approaches should be studied in detail to reach the optimal solutions as much as possible in these kind of problems.

When only subjective attributes evaluations are investigated as in "Fig. 15", Option 4 and Option 5 have the good preference evaluations. In other words, they are indifferent in the subjective evaluation. Similarly, Option 1 and Option 3 have the same evaluation (poor).

The firm energy (GWh) evaluation and the secondary energy $(\mathrm{GWh})$ evaluation are very important in the power plants investment analysis, because the aim of these investments are only generating electricity, nothing else. If there isn't any electricity generation achieved (no electricity generation), then all types of resources such as money, time and manpower are wasted (waste, loose). Generally speaking, firm energy is more important than secondary energy in practical daily life. Total energy generation is the most important one amongst three of these attributes. When the firm energy attribute and the secondary energy attribute evaluations are made by help of "Fig. 16", it is observed that Option 5 and Option 3 have both the high preference evaluations. Option 1 has the high firm energy preference evaluation, but low secondary energy preference evaluation. Option 2 and Option 4 have both the low firm energy preference and the high secondary energy preference evaluations. This total energy, firm energy, and secondary energy (GWh) evaluations are very crucial for experts, decision makers and expert decision makers in energy industry (electricity generation industry).

Another important investigation is between the investment cost (million USD) and the electricity generation features of private small hydropower plant investments. As explained in above paragraphs and sections, the electricity generation features of private small hydropower plant investments considers the firm energy and the secondary energy attributes in its utility function. Henceforth, evaluations of these two items show the benefits (gains) and the costs (looses) at the same time. In simple expressions, Option 1 has the low costs, but the high gains. Option 2 has also the low costs, but the medium gains. Option 3 and Option 5 have both the high costs and the high gains. Option 4 is the worst one, because it is located in the high costs and the medium gains point.

The final investigation in this study is made on three aggregate nodes "Private Small Hydropower Plant Preference", "Objective Attributes Evaluation" and "Subjective Attributes Evaluation" at the same time as shown in "Fig. 18". Option 5 has almost reach to the corners of the pyramid, which means that Option 5 has the highest preference evaluations in this study. Option 3 and Option 4 get the middle preference evaluations and finally Option 1 and Option 2 get placed in the low preference positions.

In very short summary, the findings of this experimental research DEXi decision model recommends to the experts, the decision makers, the expert decision makers and the investors that Option 5 should first be investigated in detail and afterwards Option 4 and Option 3 should be studied in detail, before making any small hydropower plant investment decisions and taking any action for investments. 


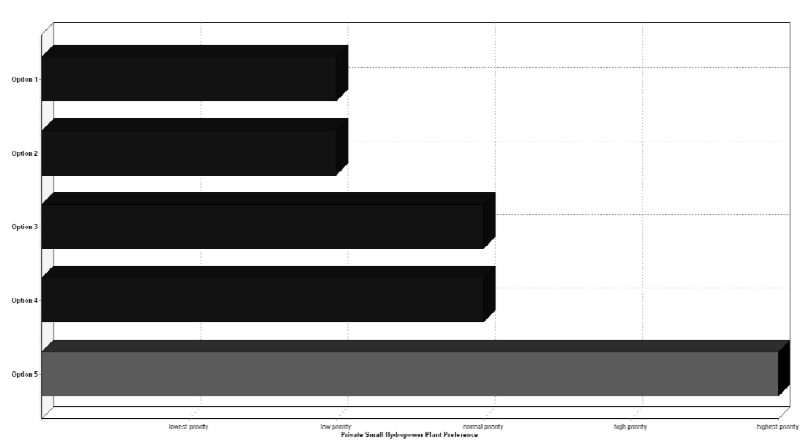

Figure 13. Private Small Hydropower Plant Preference on the DEXi (generated by the DEXi \& the Paint.NET).

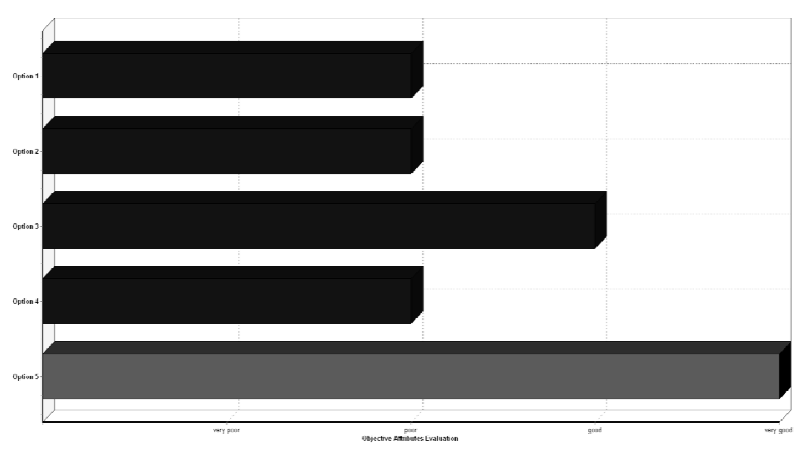

Figure 14. Objective Attributes Evaluation on the DEXi (generated by the $D E X i$ \& the Paint.NET).

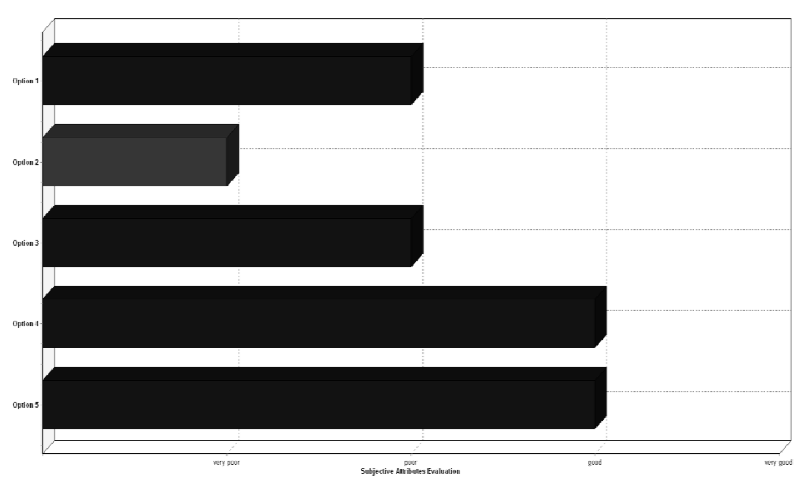

Figure 15. Subjective Attributes Evaluation on the DEXi (generated by the DEXi \& the Paint.NET).

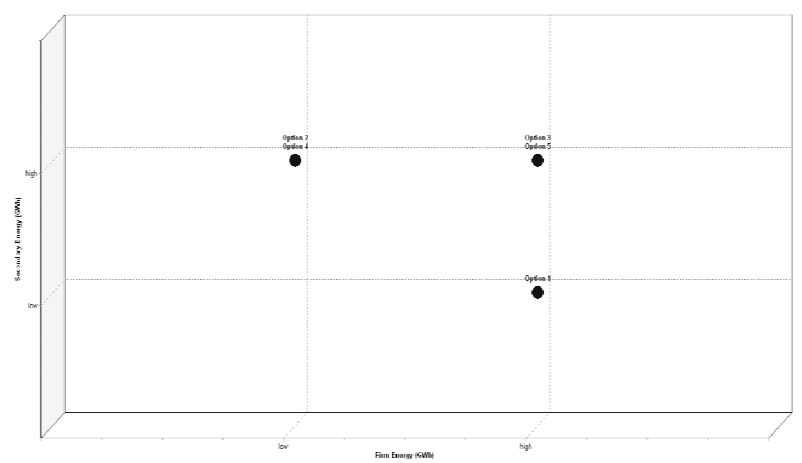

Figure 16. Firm Energy (GWh) \& Secondary Energy (GWh) Evaluation on the DEXi (generated by the DEXi \& the Paint.NET).

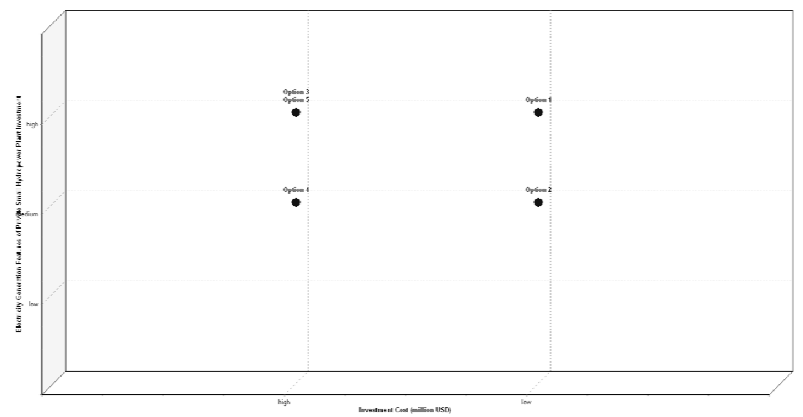

Figure 17. Investment Cost (million USD) \& Electricity Generation Features of Private Small Hydropower Plant Investment Evaluation on the DEXi (generated by the DEXi \& the Paint.NET).

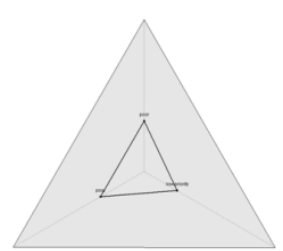

(a)

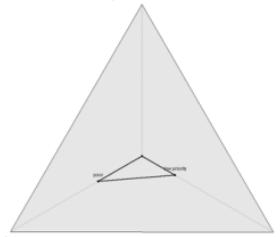

(b)

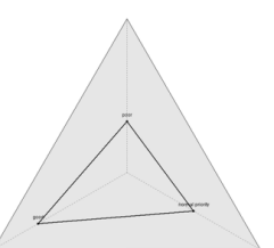

(c)

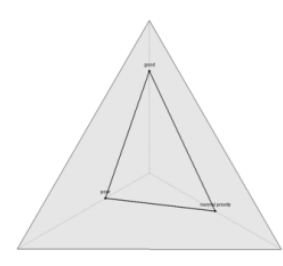

(d)

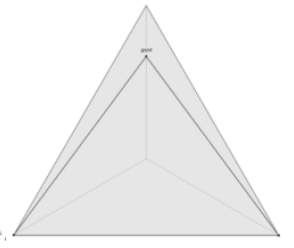

(e)
Figure 18. Private Small Hydropower Plant Preference (right corner) \& Objective Attributes Evaluation (left corner) \& Subjective Attributes Evaluation (top corner) Option 1 (a), Option 2 (b), Option 3 (c), Option 4 (d), Option 5 (e) on the DEXi (generated by the DEXi \& the Paint.NET).

\section{Conclusions, Future Applications and Research}

In this paper, the DEXi decision making approach is applied to determine the best solution of a private small hydropower plant investment selection problem in the energy industry in the Turkish private small hydropower electricity generation market. It is observed that DEXi method has some advantages for gathering the expert's opinion, because it uses the words (daily words) for the evaluations. The disadvantages of the DEXi method are also experienced during this study, such as the modeling difficulty with increasing the attributes, and the utility function definition complication with increasing the attributes. It is very well experienced and understood during this experimental research study, that the number of alternatives and the number of attributes are two important issues to be considered in these kinds of studies. When the number of attributes are increased in these kind of studies, the total effort required for the modeling, the evaluation and the analysis increases very much.

It is hoped that the decision making process in the private small hydropower industry will deeply be studied and 
understood with these kinds of studies. An autonomous computer based intelligent decision support system or executive support system for the private small hydropower plant investments can only be imagined, designed, planned, developed, demonstrated and deployed after deeply studying and understanding all of the items of the small hydropower plant investments. A few of these items are humans, small hydropower plants, real world investments, and decision making models.

During taking these small steps for developing an autonomous computer based intelligent decision support system or executive support system, the real world applications will hopefully help experts, decision makers, expert decision makers, and investors. Their happiness and satisfaction with their investments is very important for the economic growth and the wealth of our world. It is believed that humankind can only fight against hunger and malnutrition by help of sufficient scientific tools in the real world investments. One of them is tried to be investigated and presented in this study.

\section{References}

[1] Chandran, V.G.R., Sharma, S., and Madhavan, K.. "Electricity consumption-growth nexus: The case of Malaysia". Energy Policy, Vol. 38, No. 1, pp.606-612 (2010).

[2] Cook, P. "Infrastructure, rural electrification and development. Energy for Sustainable Development", Vol. 15, No. 3, pp.304-313 (2011).

[3] Dalgaard, C.J. and Strulik, H. "Energy distribution and economic growth". Resource and Energy Economics, Vol.33, No.4, pp.782-797 (2011).

[4] World Bank. http://data.worldbank.org accessed in 05/09/2013 (2013).

[5] Republic of Turkey Energy Market Regulatory Authority, http://www.emra.gov.tr/index.php/electricity-market/legislatio $\mathrm{n}$ accessed in 17/07/2015 (2015).

[6] Open Energy Information. "Transparent Cost Database Levelized Cost Of Electricity", http://en.openei.org/apps/TCDB/ accessed in 17/07/2015 (2015).

[7] National Laboratory of the U.S. Department of Energy Simple. "Levelized Cost of Energy (LCOE) Calculator Documentation", http://www.nrel.gov/analysis/tech_lcoe_documentation.html accessed in 17/07/2015 (2015).

[8] Khatib, H. Economic Evaluation of Projects in the Electricity Supply Industry, London: The Institution of Engineering and Technology, (2003).

[9] National Laboratory of the U.S. Department of Energy Simple Levelized. "Cost of Energy Calculator" http://www.nrel.gov/analysis/tech_lcoe.html accessed in 17/07/2015 (2015).

[10] European Renewable Energy Council. "REN21 Renewables 2012 Global Status Report". European Focus, Paris, France (2012).
[11] Dragu, C., Sels, T., and Belmans, R. "Small hydro power-state of the art and applications". ESAT-ELEN, Energy Institute, Leuven, Belgium (2010).

[12] Republic of Turkey Energy Market Regulatory Authority. "Hydropower Plant Licenses" http://lisans.epdk.org.tr/epvys-web/faces/pages/lisans/elektrik Uretim/elektrikUretimOzetSorgula.xhtml accessed in 17/07/2015 (2015).

[13] State Hydraulic Works. "Hydropower Plant Licenses" http://www.dsi.gov.tr/faaliyetler/hessu-kullanim-anlasmalari accessed in 17/07/2015 (2015).

[14] Investopedia (2015). http://www.investopedia.com/ accessed in $17 / 07 / 2015$.

[15] Saaty, T.L. "How to make a decision: The Analytic Hierarchy Process". European Journal of Operational Research, Vol.48, pp.9-26, (1990).

[16] Saaty, T.L. "Relative Measurement and Its Generalization in Decision Making Why Pairwise Comparisons are Central in Mathematics for the Measurement of Intangible Factors The Analytic Hierarchy/Network Process". RACSAM (Revista Serie A Matemáticas: Rev. R. Acad. Cien. Serie A. Mat.), Vol. 102, No. 2, pp.251-318, (2008).

[17] Bohanec, M. DEXi: Program for multi-attribute decision making user's manual version 4.00. Ljubljana: Jožef Stefan Institute, (2013).

[18] Roy, B. "The outranking approach and the foundations of ELECTRE methods". Theory and Decision, Vol.31, pp.49-73 (1991).

[19] Brans, J.P., and Vincke, P.H.. "A preference ranking organisition method: The PROMETHEE method for MCDM". Management Science, Vol.31, No.6, pp.647-656 (1985).

[20] Google Scholar. "'power" AND "DEXi" search results" http://scholar.google.com.tr/scholar?start $=990 \& \mathrm{q}=\% 22$ power $\% 22+\% 22 \mathrm{DEXi} \% 22 \& \mathrm{hl}=$ en\&as sdt=1,5\&as vis $=1$ accessed in $17 / 07 / 2015$ (2015).

[21] Bohanec, M., Znidarsic, M., Rajkovic, V., Bratko, I., and Zupan, B.. "DEX Methodology: Three Decades of Qualitative Multi-Attribute Modeling". Informatica, Vol.37, pp.49-54, (2013).

[22] Efstathiou, J., and Rajkovič, V.. "Multiattribute decisionmaking using a fuzzy heuristic approach". IEEE Trans. on Systems, Man, and Cybernetics, SMC-9, pp.326-333, (1979).

[23] Bohanec, M., Bratko, I., and Rajkovic, V. "An expert system for decision making". Processes and Tools for Decision Making (ed. H.G. Sol), North-Holland, pp.235-248, (1983).

[24] Bohanec, M., Rajkovic, V. "DEX: An expert system shell for decision support". Sistemica, Vol.1, No.1, pp.145-157, (1990).

[25] Saracoglu, B.O. "An Experimental Research Study on the Solution of a Private Small Hydropower Plant Investments Selection Problem by ELECTRE III/IV, Shannon's Entropy, and Saaty's Subjective Criteria Weighting", Advances in Decision Sciences, Vol. 2015, Article ID.548460, 20 pages (2015). doi:10.1155/2015/548460 
[26] Saracoglu, B.O. "An AHP application in the investment selection problem of small hydropower plants in turkey", International Journal of the Analytic Hierarchy Process, in press.

[27] Dictionary.com. "drainage basin" http://dictionary.reference.com/browse/drainage\%20basin accessed in 18/07/2015 (2015).

[28] U.S. Department of the Interior, U.S. Geological Survey, The Water Cycle - USGS Water Science School, "Surface Runoff The Water Cycle"

http://water.usgs.gov/edu/watercyclerunoff.html accessed in 21/07/2015 (2015).

[29] US Energy Information Administration. "net head" http://www.eia.gov/tools/glossary/index.cfm accessed in $18 / 07 / 2015(2015)$.

[30] U.S. Department of the Interior, U.S. Geological Survey, "How Streamflow is Measured Part 2: The discharge measurement" http://water.usgs.gov/edu/streamflow2.html accessed in 21/07/2015 (2015).

[31] ESHA (European Small Hydropower Association). "Guide on How to Develop a Small Hydropower Plant", Brussels, Belgium, (2004).

[32] NPTEL (National Programme on Technology Enhanced Learning) "Water Resources Engineering Dr. Dhrubajyoti Sen" http://nptel.ac.in/downloads/105105110/ accessed in 18/07/2015 (2015).

[33] Wikia. "community attitudes" http://psychology.wikia.com/wiki/Community_attitudes accessed in 18/07/2015 (2015).

[34] Merriam-Webster. "transportation" http://www.merriam-webster.com/dictionary/transportation accessed in 21/07/2015 (2015).

[35] Vocabulary.com "topography" http://www.vocabulary.com/dictionary/topography accessed in 21/07/2015 (2015).

[36] University of Minnesota, Department of Earth Sciences, Newton Horace Winchell School of Earth Sciences. "What is Earth Science" https://www.esci.umn.edu/whatis accessed in
$21 / 07 / 2015(2015)$

[37] Oxford University Press. "security" http://www.oxforddictionaries.com/definition/english/security accessed in 21/07/2015 (2015).

[38] Terrorism-Research.com. "terrorism" http://www.terrorism-research.com/ accessed in 21/07/2015 (2015).

[39] IUCN, International Union for Conservation of Nature. "What is a protected area?"

https://www.iucn.org/about/work/programmes/gpap_home/pas _gpap/ accessed in 21/07/2015 (2015).

[40] Patrick, D.R., Fardo, S.W. Electrical distribution systems, 2nd ed. Lilburn: The Fairmont Press, (2009).

[41] Carrot2. http://search.carrot2.org/stable/search accessed in $18 / 07 / 2015$ (2015).

[42] Zamir, O., and Etzioni, O. "Grouper: a dynamic clustering interface to Web search results". Computer Networks, Vol.31, No.11, pp.1361-1374, (1999).

[43] Osinski, S., and Weiss, D. "A concept-driven algorithm for clustering search results". Intelligent Systems, IEEE, Vol.20, No.3, pp.48-54, (2005).. DOI:10.1109/MIS.2005.38

[44] Miller, G.A. "The magical number seven, plus or minus two: some limits on our capacity for processing information". The Psychological Review, Vol.63, pp.81-97 (1956).

[45] Shiffrin, R.M., and Nosofsky, R.M. "Seven plus or minus two: a commentary on capacity limitations". Psychological Review, Vol.101, No.2, pp.357-361 (1994).

[46] Kintsch, W., and Cacioppo, J.T. "Introduction to the 100th anniversary issue of the psycological review". Psychological Review, Vol.101, No.2, pp.195-199, (1994).

[47] Schweickert, R., and Boruff, B. "Short-term memory capacity: Magic number or magic spell?". Journal of Experimental Psychology: Learning, Memory, and Cognition, Vol.12, No.3, pp.419-425 (1986).

[48] DEXi Version 4.00 Help Manual 